\title{
ENERGY PROCESSES OF MUCOCILIARY CLEARANCE
}

\author{
Vadim S. Isachenko ${ }^{1}$, Lubov V. Minaeva ${ }^{2}$, Vladimir V. Dvorianchikov ${ }^{1}$, Vasiliy \\ G. Mironov ${ }^{1}$, Ksenia V. Vinichenko ${ }^{1}$, Andrey V. Shafigulin ${ }^{1}$, Iliyan Doykov ${ }^{3}$, \\ Dilyana Vicheva ${ }^{3}$ \\ 1) Department of Otorhinolaryngology, S.M. Kirov Military Medical Academy, \\ St. Petersburg, Russia, \\ 2) Department of Clinical biochemistry and laboratory diagnostics, S.M. Kirov \\ Military Medical Academy, St. Petersburg, Russia, \\ 3) Department of Otorhinolaryngology, Medical Faculty, Medical University, \\ Plovdiv, Bulgaria.
}

\begin{abstract}
The main objective of the paper is to describe in detail physiology and pathophysiology of mucociliary transport system. Mucociliary clearance (MCC) is a principal component of the respiratory tract. As an important defense mechanism, it provides the necessary potential for the barrier and immune function of the airway. The paper gives an overview of factors affecting the bioenergetic processes in ciliated epithelium. It focuses the study ciliary movement performance, generated by adenosine triphosphate hydrolysis.
\end{abstract}

Keywords: activity of ciliated epithelium, bioenergetic processes,

\section{BACKGROUND}

Over the past twenty years, an increase in number of chronic respiratory diseases worldwide is observed, alongside with a decrease in the age of the patients.

Today the causes of incidence rate increase are learned. They include chronic stress, environmental pollution with emissions of resistant and non-decomposing pollutants (owing also to environmental disasters of a global scale), low physical activity, bad habits (smoking, alcohol abuse), unbalanced diet (with a high content of easily digestible carbohydrates, transgenic fats, lack of macro- and micronutrients), leading to an increase in comorbidity (abdominal obesity, gastro esophageal reflux disease, sleep apnea, hypothyroidism), together with drug abuse (vasoactive, antihistamine, antibacterial drugs, nonsteroidal anti-inflammatory drugs). According to World Health Organization, diseases of the respiratory system will be the second of the main causes of death in the XXI century [1].

Upper respiratory tract pathology, such as diseases of the nose and paranasal sinuses represents the most common respiratory disease.

According to epidemiological investigations, 40\% of the human population periodically notes the presence of certain symptoms of this pathology, and $20 \%$ suffer from chronic rhinitis.

Given the significant success in understanding the etiological and pathogenetic processes, the development and use of modern effective pharmaceuticals, the number of patients undergoing inpatient treatment for diseases associated with pathology of the mucous membranes of the upper respiratory tract and sinuses increases annually by $1.5-2 \%$ [2].

With the airway aerodynamics dysfunction the necessary warming with the humidification of the inhaled air does not occur.

Physiologically abnormal mouth breathing is accompanied by a decrease in the depth of inhalation, and as a result, only $78 \%$ of the required amount of oxygen enters the lungs. Lack of partial pressure of the air jet on the mucous membrane of the nasal cavity leads to dysfunction of the respiratory reflex and disturbance of the intracranial hemodynamic. All these factors are reflected in the functional state of the cardiovascular system, and also lead to a whole complex of neurological problems such as: headache, fatigue, memory loss, etc.

\section{Mucociliary clearance}

The nasal cavity and the adjacent sinuses represent a unique unified functional system that provides adaptation and protection from adverse environmental factors. Mucociliary clearance is acting as the main mechanism of protection of the mucous membrane. Mucociliary clearance allows removing from the nasal cavity and paranasal sinuses up to $100 \mathrm{ml} /$ day of mucus with pathogens contained in it (bacterial and fungal cells, viruses (up to $60 \%$ ), allergens, air pollutants larger than 8 microns), thereby, not allowing the pathological process to develop $[3,4]$.

In connection with the above matter, the malfunction of the mucociliary clearance should be considered as the main link in the pathogenesis of all diseases of the upper respiratory tract [5]. 
The effectiveness of MCC is guaranteed by normal frequency of cilia movement, viscosity of nasal secretion, and a number of other factors. The ciliary beat frequency $(\mathrm{CBF})$ is the primary evaluation parameter of proper functioning of ciliary apparatus.

The cilium is an organelle which consists of two interdependent parts - the cilium itself and the basal body (Figure 1).

Fig. 1. General view of the ciliary cell of the mucous membrane of the human respiratory tract. Ciliated cells taken from bronchoalveolar lavage. Magnification: $10 \times 1000$

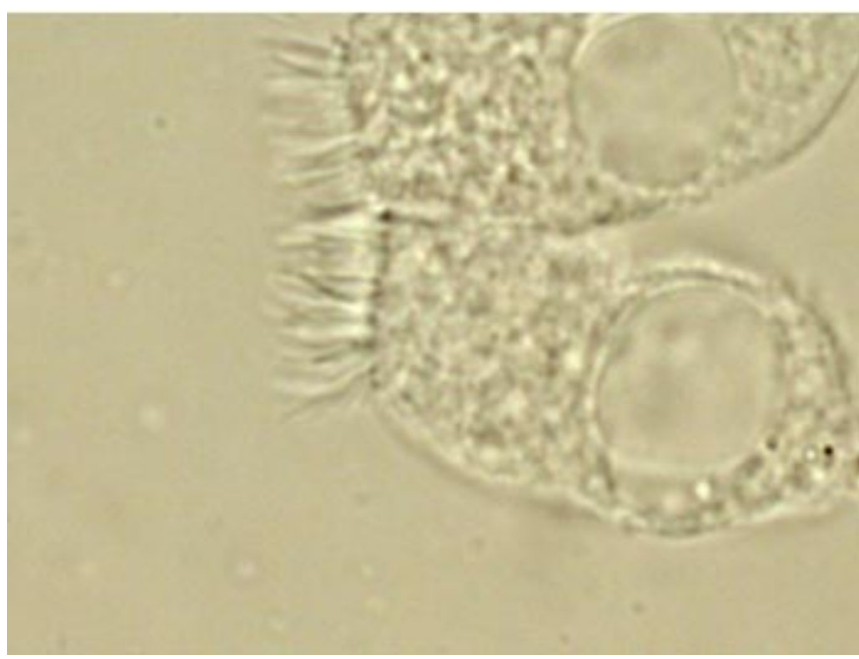

The length of cilia varies in a range of 5 to $10 \mathrm{mi}-$ crons, with diameter of 0.1-0.2 microns. 9 paired fibrils pass through the matrix (nexin). In the centre there are 2 unpaired tubular fibrils that are seen under ultramicroscopic examination (Figure 2). Cilium arises from a basal body located at the apical pole of the cell $[6,7]$. These tubular fibrils are anchored to the base of the ciliary membrane. There are 2 unpaired tubular fibrils in the centre of the cilium. The tubules are connected by various chemical bonds. Communication peptides organize a unified coordinated system of microtubules. The peripheral microtubule pairs are connected to each other by special protein - nexin $(\mathrm{N})$. Doublet microtubules are connected with two central single microtubules by protein complexes having the appearance of radial spokes $(\mathrm{S})$. The spoke heads $(\mathrm{G})$ are attached to the inner sheath, which connects the two central singlet microtubules (Figure 2, 3).
Fig. 2. The structure of the cilia.

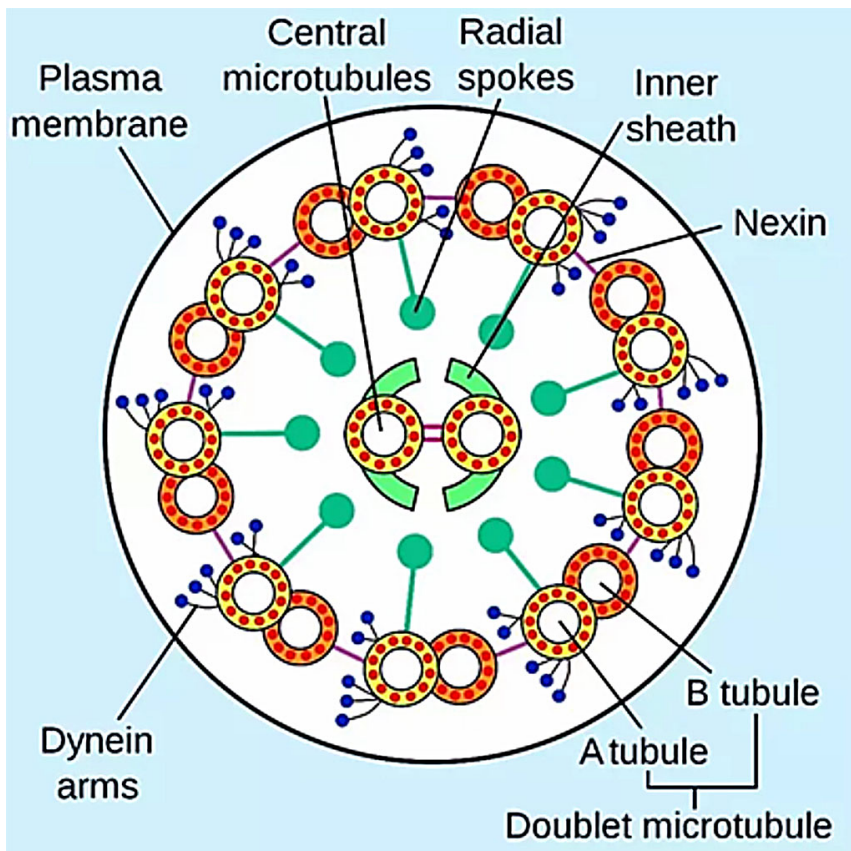

Fig. 3. A scheme reflecting the nature of the association of microtubules with motors represented by dyenein protein

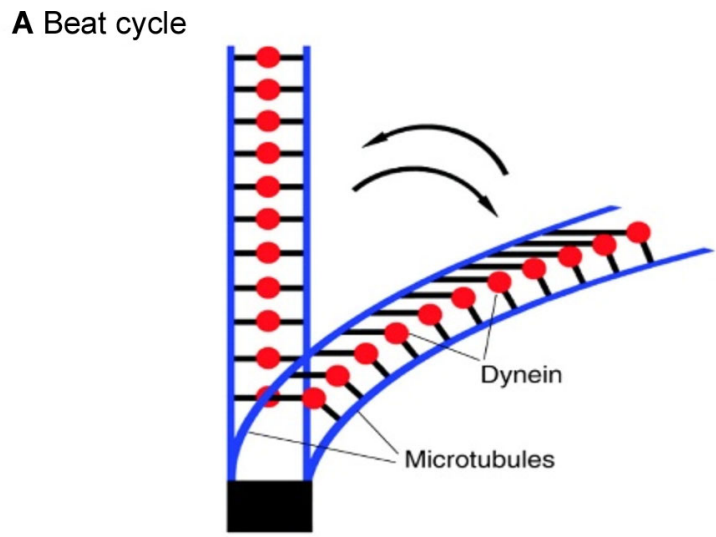

B Dynein cross-bridge cycle

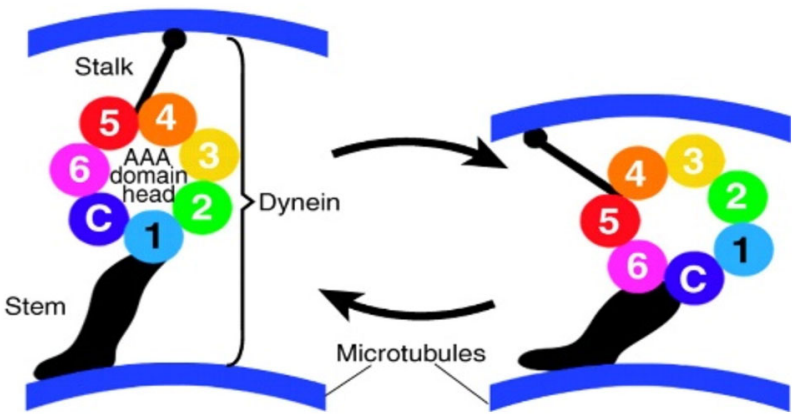




\section{Mechanism of ciliary beat}

Dyneins which are not connected with the external microtubules drive cilia bending. The activation of dyneins appears sequentially both along the length and on the periphery of the axoneme. Spokes and central microtubules containing kinases and phosphatases are multidirectional enzymes that control dynein activity. The activation signal of dynein is triggered when the central tubules rotate around its axis. Ciliary motility is driven by the coordinated activities of dynein isoforms [8].

It should be noted that the cilium has a basal body located at its base. The structure of this basal body resembles centriole.

The peripheral cellular contractile system is functionally connected with the system of peripheral microtubules. Contractile proteins (actin, myosin, tropomyosin) located mainly around two central singlet microtubules and radial spokes, bind the central support cylinder with peripheral microtubules. Microtubules are formed by 13 dimeric globular proteins, $80 \%$ of which are alpha and beta tubulins, and the remaining $20 \%$ are MAP1, MAP2 and low-molecular-weight tau [9].

\section{Function of motor proteins}

The mechanism of tubulin-dynein complex movement is accomplished by sliding. The chemical energy of adenosinetriphosphate (ATP) is converted into mechanochemical energy due to tubulin-dynein produced sliding of the adjacent outer doublet microtubules [11].

The hydrolysis of macroergic bond of ATP ensures the energy processes of the motors.

The conformational rearrangements of proteins of the ATP domains trigger the generation of adenosine diphosphate (ADP) and phosphoric acid and the released chemical energy is converted to mechanical energy which is used for movement.

According to the results of biochemical studies, the major energy currency molecule of the cell, ATP, localized exclusively in nine peripheral microtubules. It should be noted that high enzymatic activity in the basal body one way or another participates in the synthesis of ATP and the activation of contractile protein structures: succinate dehydrogenase, alkaline phosphatase, aminopeptidase; on the surface and body of cilia - adenylate cyclase, $\alpha$-Glycerophosphate dehydrogenase and acetylcholinesterase [9]. According to Toyoaki Ohbuchiu Hideaki Suzuki specific protein structures play a large role in synchronization of ciliary beating processes: pannexins and connexins in nasal mucosal epithelia of the nasal cavity and paranasal sinuses. Pannexins and connexins participate in the generation of intercellular calcium waves in which calcium-mediated signalling responses spread to contiguous cells through the gap junction and modulation of the biliary rhythm via ATP release, and also in regulation of mucus blanket components via $\mathrm{H}_{2} \mathrm{O}$ efflux [10].

\section{Factors affecting bioenergy processes}

ATP is the main energy-supplying molecule of the ciliated epithelium, which controls the intensity and activity duration of ciliary apparatus.

The study of the processes associated with the bioenergy exchange of ATP in the cells of the ciliary epithelium does not lose its relevance at the present time. Searches for effectors of ATP synthesis in various directions are underway.

The effect of the exogenous effect of the macroerg itself on the cells of the ciliary epithelium is investigated first. With the introduction of ATP (100 ìmol) in vitro on the nasal ciliary epithelium of healthy volunteers, the ciliary beat frequency increased by $50-70 \%$. This result can be explained by the fact, that ATP does not directly penetrate the epithelial membrane, but acts indirectly via adenosine - a product of catabolic metabolism of ATF and purinergic receptors activation. Probably at the same time there is an activation of the synthesis of this macroerg inside the cell along the storage path due to the phosphorylation of adenosine. [12, 13, 14, 15].

The experiment with placing ciliary epithelium cells in a solution of $0.005 \%$ phosphoric acid increased the ciliary motor activity by $143 \%$, a further increase in the acid concentration to $0.05 \%$ was accompanied by an increase in the rate of MCT by only $99 \%$ compared with the control indicators. The use of $0.1 \%$ phosphoric acid led to a reduction in ITC by $98 \%$ with control.

The use of $0.005 \%$ acetic acid increased the frequency of ciliary beating by 1.7 times in comparison with the control group, the introduction of $0.05 \%$ acetic acid increased the frequency of ciliary beating by only $45 \%$ relative to the control value. However, the use of $0.1 \%$ acetate already leads to a decrease in the speed of ITC in 2 times in comparison of the control value.

The results obtained clearly demonstrate the inverse relationship of the acid and base state and the activity of mucociliary transport.

Wherein, the organic acid (acetic) undoubtedly gives a stronger effect than the inorganic (phosphoric acid).

At the same time, the efficiency of using phosphoric acid can quite possibly be explained by the effect on the processes of enhancing the phosphorylation of ADP due to an increase in the concentration of phosphoric acid [16].

The increase in the concentration of the above mentioned acids, associated with the arrest of the motor activity of the epithelium, is determined by the denaturation of proteins from subcellular structures. There is some evidence that the acid "stop" is reversible. Thus, when ciliated cells are transferred from a strong acid solution to a weak one, a rapidly passing recovery of cilia occurs, when the placement of ciliated cells in a weakly alkaline solution leads to a steady recovery. 


\section{DISCUSSION:}

Any form of motor activity is always associated with the oxygen supply and maintaining the normal biological oxidation processes. It is hypoxia that underlies many diseases, since the only effective source of energy is oxidation with oxygen. Adaptation to lowering oxygen tension and oxygen content in blood depend not on transition to anaerobic processes of synthesis, but rather on the increase of level of tissue oxygenation, changes in the sensitivity to oxygen of respiratory enzymes and an increase in the respiratory surface area of mitochondria, which is partially confirmed by the increased mitochondrial condensation during hypoxia.

Since the synthesis of ATP in the epithelial cell is directly related to the partial pressure of oxygen, an increase in its content will lead to the oxidative phosphorylation process. This fact demonstrates the results of the study about the use of oxygen therapy for the treatment of chronic rhinosinusitis. (Enteral oxygen therapy in the form of receiving oxygen cocktails. Concentrator "ARMED" was used for the formation of $\mathrm{O}_{2}$, oxygen concentration $-95 \%$ of ambient air.)
An increase in the diffusion of oxygen into ciliated epithelium cells is associated with increased ATP synthesis due to the activation of oxidative phosphorylation. This statement is proved by the results of research studies of the effect of hypercapnia on the motor activity of the ciliary epithelium - a high concentration of $\mathrm{CO}_{2}$ inhibits the movement of cilia $[17,18,19]$.

The use of the developed method of artificial ventilation of the nasal cavity with a constant positive pressure in patients on artificial lung ventilation improves the efficiency of MCC by increasing ciliary beat frequency in ciliated epithelium of the nasal cavity, indirectly improving the energy supply in cells [14].

\section{CONCLUSION}

Taking all the aforesaid into consideration, we can say that further detailed study of the biochemical processes of energy supply of ciliated cells will help to find the most effective ways to activate the MCC, i.e. to treat the diseases of the upper respiratory tract.

The authors have no conflict of interest to declare.

\section{REFERENCES:}

1. Sadovnikova II. [The need and possibilities for the correction of mucociliary clearance in the pathology of the respiratory system.] [in Russian] Russkiy Meditsinskii Zhurnal. 2012; (6):320-32.

2. Stepanov EN. [The role of the rhinal mucous membrane microcirculation's disbalance in pathogenesis of different types of chronic rhinitis.] [in Russian] Prakticheskaya meditsina. 2011; 51(3): 11-14.

3. Bodzhokov AR. [Can the speed of mucociliary transport of the mucous membrane of the nasal cavity serve as an expert test?] [in Russian] Basic research. Sochi. 2007; 382-383.

4. Subbotina MV, Dudkin SV. [The effect of fusafungine on mucociliary transport in the nasal mucosa of healthy people.] [in Russian] Consilium Medicum. 2009; 11:40-44.

5. Zavalii AA, Kubyshkin AV. [Pathogenetic value of investigation of mucociliary transport system functional state to improve rhinosinusitis diagnosis.] [in Russian] Folia Otorhinolaryngologiae et Pathologiae Respiratoriae. 2016; 22(1):38-47. [elibrary.ru]

6. Tilley AE, Walters MS, Shaykhiev R, Crystal RG. Cilia Dys- function in Lung Disease. Annu Rev Physiol. 2015; (77): 379-406. [PubMed] [Crossref]

7. Bustamante-Marin XM, Ostrowski LE. Cilia and Mucociliary Clearance. Cold Spring Harb Perspect Biol. 2017 Apr 3;9(4). pii:a028241. [PubMed] [Crossref]

8. Zavalii MA. [Comparative histology and physiology of the respiratory epithelial ciliated apparatus.] [in Russian] Tavricheski jmediko-biologicheski jvestnik. 2014; 17(2): 46-53. [in Russian]

9. Lutsenko MT. [Morphofunctional characteristic of airway ciliary epithelium: new scientific information to the previous views.] [in Russian] Bulletin physiology and pathology of respiration. 2015; 57:120129.

10. Ohbuchi T, Suzuki H. Synchronized roles of pannexin and connexin in nasal mucosal epithelia. Eur Arch Otorhinolaryngol. 2018 Jun;275(6): 1657-1661. [PubMed] [Crossref]

11. Gross SP, Welte MA, Block SM, Wieschaus EF. Coordination of opposite-polarity microtubule motors. J Cell Biol. 2002 Feb 18;156(4):71524. [ubMed] [Crossref]

12. Laberko EL, Bogomil'skii MR.
[Modern view on mucocilicry Clearence Regulation: a literature review.] [in Russian] Vestnik RGMU. 2015(1): 60-64.

13. Geppe NA, Ozerskaya IV. [Factors affecting the state of the ciliary epithelium and mucociliary clearance.] [in Russian] Effektivnaya farmakoterapiya. 2011(33): 24-28.

14. Modis K, Gero D, Stangl R, Rosero O, Szijarto A, Lotz G, et al. Adenosine and inosine exert cytoprotective effects in an in vitro model of liver ischemia-reperfusion injury. Int J Mol Med. 2013 Feb;31(2):43746. [PubMed] [Crossref]

15. Nascimento FP, Macedo-Junior SJ, Pamplona FA, Luiz-Cerutti M, Cordova MM, Constantino L, et al. Adenosine A1 receptor-dependent antinociception induced by inosine in mice: pharmacological, genetic and biochemical aspects. Mol Neurobiol. 2015; 51(3):1368-78. [PubMed] [Crossref]

16. Burikov AA, Kutenko MA, Nekhoroshii AA. [Possibility of application of ciliary epithelium in the medical microbioroboto engineering.] [in Russian] Izvestiya Yuzhnogo federal'nogo universiteta. 2009;(10): 203-208. 
17. Namazov LS, Konova OM, Il'in AG. [The use of oxygen cocktails made with the use of an oxygen concentrator and a cocktail maker in the prevention and treatment of bronchopulmonary diseases in children.] Moskow: GU NTSZD RAMN. 2008. p. 20-21. [in Russian]

18. Baby MK, Muthu PK, Johnson P, Kannan S. Effect of cigarette smoking on nasal mucociliary clearance: A comparative analysis using saccharin test. Lung India. 2014; 31(1):39-42. [Crossref]

19. Proenca M, Fagundes Xavier R, Ramos D, Cavalheri V, Pitta F, Cipulo Ramos EM. [Immediate and short term effects of smoking on nasal mucociliary clearance in smokers]. [in Portuguese] Rev Port Pneumol. 2011 Jul-Aug;17(4):172-6. [PubMed] [Crossref]

Please cite this article as: IsachenkoVS, Minaeva LV, Dvorianchikov VV, Mironov VG, Vinichenko KV, Shafigulin AV, Doykov I. Vicheva D. Energy processes of mucociliary clearance. J of IMAB. 2019 Apr-Jun;25(2):2570-2574.

DOI: https://doi.org/10.5272/jimab.2019252.2570

Received: 20/01/2019; Published online: 19/06/2019

\author{
Address for correspondence: \\ Vadim S. Isachenko MD, \\ Department of Otorhinolaryngology, Federal State Military Educational Insti- \\ tution of the Higher Professional Education "SM Kirov Medical Military Acad- \\ emy" of Ministry of Defence of the Russian Federation, \\ Contact number: +78122923342 . \\ 194044, Sankt-Petersburg, St. Ac. Lebedeva 6-P, Russia. \\ E-mail: isachen@yandex.ru,
}

